\title{
AS REPRESENTAÇÕES SOCIAS: Etnias Moçambicanas
}

SOCIAL REPRESENTATIONS: Moçambican ethnicities

LAS REPRESENTACIONES SOCIALES: Etnias Moçambicanas

\section{Antonio Francisco Sefane}

Doutor em Psicologia Social pela Universidade John Kennedy. Professor da Universidade UniSave Moçambique. assefas5@gmail.com.

\section{0-0002-7711-4773}

\section{Joseneide dos Santos Gomes}

Doutora em Psicologia Social pela Universidade John Kennedy. Professora da Prefeitura de São Paulo. santos.joseneide@ig.com.br.

\section{0-0002-8274-9685}

Correspondência: Universidade Save. Estrada Nacional1. Parcela 76 Chongoene Xai-Xai Gaza, 1200 Moçambique.

Recebido em: 12.10.2020.

Aceito em: 20.11.2020

Publicado em: 01.01.2021.

\section{RESUMO:}

O presente artigo, visa trazer uma reflexão sobre a teoria das Representações Sociais na óptica da Psicologia Social. A partir da revisão bibliográfica, faz-se uma analogia

\begin{abstract}
das teorias das representações sociais, a uma sociedade concreta, neste caso, a sociedade Moçambicana. As representações sociais, tem sido um tema amplamente discutido por vários e categorizados autores, muitos deles abordando a relação cognição-conhecimento, indivíduo e sociedade. Para o efeito, foram analisadas três etnias moçambicanas, nomeadamente, Macuas-Lomués, Ndaus e Tsongas, nas quais, a partir da constatação bibliográfica das sua culturas, crenças e valores, pode se fazer uma analogia real entre as teorias sobre as representaçãoes sociais e os comportamentos destas etnias, que deixam claras as diferentes representações socias nas diferentes regiões que formam o país chamado Moçambique. A base da pesquisa foi a revisão bibliográfica, tanto para abordar os suportes teóricos, assim como para abordar a realidade Moçambicana.
\end{abstract}

PALAVRAS-CHAVE: Represntações; Etnias; Macuas; Tsongas

\section{Introdução}

Na definção clássica segundo Jodelet (1985), as representações sociais, são modalidades de conhecimento prático orientados para a comunicação e para a compreensão do contexto social, material e ideativo em que vivemos.

Por sua vez, Fuller (1988) destaca a contribuição que a Psicologia Social vem dar ao desmestificar a dicotomia entre indivíduo e sociedade, e entre psicologismo e sociologismo. "O psicologismo, envolve a avaliação do estado mental que o produtor traz para o processo de conhecimento, enquanto o sociologismo, envolve a avaliação das conseqüências do processo de conhecimento — os produtos do conhecimento sem levar em consideração o estado mental do produtor".

Fuller (1988) continua afirmando que, a Psicologia Social procura superar esta dicotomia visualizando o indivíduo e suas produções mentais como produtos de sua socialização em um determinado segmento social. A individualidade, nesta perspectiva, emerge como uma estrutura estruturada que tem potencial estruturante.

É neste contexto, que a peresente pesquisa basear-se-á nesta abordagem da Psicologia Social para fazer a analogia entre o que os autores dizem a cerca das 
representações sociais e tentar traduzir as abordagens filosóficas /teóricas a uma realidade moçambicana.

\section{Abordagem teórica do tema}

Na perspectiva de Vigoysky (1978) Indivíduo, é sempre uma entidade social e, como tal, um símbolo vivo do grupo que ele representa.

Assim, o indivíduo no grupo, próprio das abordagens quantitativas, pode ser abordado como sujeito genérico - como o grupo no indivíduo - contanto que tenhamos uma compreensão adequada do contexto social por ele habitado: seu habitus e a teia mais ampla de significados na qual o objeto de representação está localizado (Vigoysky, 1978).

Enquanto sistemas de interpretação, as representações sociais regulam a nossa relação com os outros e orientam o nosso comportamento. As representações intervêm ainda em processos tão variados como a difusão e a assimilação de conhecimento, a construção de identidades pessoais e sociais, o comportamento intra e intergrupal, as acções de resistência e de mudança social. Enquanto fenómenos cognitivos, as representações sociais são consideradas como o produto duma actividade de apropriação da realidade exterior e, simultaneamente, como processo de elaboração psicológica e social da realidade (Jodelet, 1989, p.36-37).

Para Spink (1993) esta aboradgem acima, possivelmente pode ser a contribuição mais valiosa da Psicologia Social para o estudo das representações sociais: a ênfase no processo de elaboração das representações a partir das práticas sociais que as definem e que são por elas definidas.

A teoria das representações sociais reapresenta um problema que já é, historicamente, de interesse de outras ciências humanas, como a história, antropologia e sociologia (Jodelet, 2001).

Para Vala (1996), é uma teoria científica sobre os processos através dos quais os indivíduos em interação social constroem explicações sobre objetos sociais.

Continuando, Vala (1996) falando da actividade humana que é esta que joga um papel de relevo nas representações sociais, cita alguns autores nos seguinte termos:

Na obra Princípios da Psicologia W. James (1890) refere que duas grandes orientações dominam o pensamento acerca da actividade humana: a teoria das faculdades e a teoria da associação. A primeira enfatiza a ideia do homem como uma entidade que tem capacidade para conhecer, desejar e sentir.

É nesta perspectiva que Bandura (1986) se refere às faculdades humanas básicas, como, por exemplo, a capacidade de criar símbolos, a capacidade de auto-regulação e 
de auto-reflexibilidade. Na segunda orientação o agente e as suas faculdades deixam de ser princípios explicativos para se tornarem objeto de explicação. Como refere James, «procuram-se os elementos comuns dos diversos factos mentais, mais do que o agente comum que lhes subjaz» (p. 1). As metáforas que representam estas duas orientações são, na linguagem de James, respectivamente, o «homem autónomo» e o «homem plástico». O homem autónomo é o sujeito da acção, e a acção decorre das suas faculdades. O homem plástico é «agido», é um sujeito passivo."

Moscovic (1984) diz que o psicólogo e, muitas vezes, o sociólogo, abordam os fatos. Eles geralmente usam uma chave de leitura binária. Essa chave corresponde à separação entre sujeito e objeto, que são dados e definidos independentemente um do outro. O psicólogo coloca de um lado o "ego" (o indivíduo, o organismo) e, de outro, o "objeto", ou, por um lado, um repertório de respostas e, por outro, o estímulo: Portanto, quando estudamos a percepção visual, consideramos o aparato visual e a cor ou intensidade de um ponto de luz, devido à maneira como o olho reage à estimulação da luz. Da mesma forma, ao estudar processos intelectuais, estamos interessados na maneira como o cérebro trata as informações do mundo exterior. E queremos saber como você aprende, organiza e transforma em comportamento definido. O esquema do relacionamento permanece assim:

Sujeito individual (ego, organismo) Vs Objeto (ambiente, estímulo).

Na sociologia o indivíduo é visto como uma coletividade (o grupo, a classe social, o Estado). Ou podemos levar em consideração uma multidão de sujeitos que mudam, negociam, compartilham a mesma visão de mundo. Quanto ao objeto, ele também tem um valor social, representando um interesse ou uma instituição. Além disso, o objeto é algumas vezes composta de outras pessoas, por outros grupos, que formam o que chamamos de ambiente humano. Obviamente em todos esses casos, nos encontramos diante de um sujeito e um objeto diferenciados de acordo com critérios económicos ou políticos, éticos ou históricos. Independentemente do tipo de diferenciação, o que queremos saber é como as várias categorias de indivíduos se comportam na sociedade, como reproduzem a hierarquia existente, como distribuem riqueza ou exercem seus poderes. Ou como a ação de cada indivíduo, provida de seus próprios interesses e objetivos, é transformada em uma ação coletiva (Moscovic, 1984).

Para Moscovici (1978) as Representações Sociais são entidades quase tangíveis. Elas circulam, cruzam-se e cristalizam-se incessantemente, por intermédio de uma fala, um gesto, um encontro em nosso universo cotidiano, constituindo, assim, uma modalidade de conhecimento particular que tem por função a elaboração de comportamentos e a comunicação entre os indivíduos. 
A informação é a organização dos conhecimentos que o grupo possui a respeito de determinado objeto social. Ou seja, dependendo do nível de conhecimento do grupo, as informações a respeito do objeto serão mais precisas, e sua representação pode diferir de um grupo com pouca, nenhuma informação, ou com informações diferentes (Moscovic, 1978).

Continuando a laborar sobrere o campo de representações, Moscovici (1978) considera-o a imagem que o grupo social constrói do objeto, o modelo social referente aos aspectos da representação do objeto.

\section{Algumas etnias Moçambicanas e suas características}

Moçambique é um país de grande diversidade cultural, e como a maioria dos países da África, não possui uma identidade específica, apresentando aspectos que o ligam a outros países vizinhos e mesmo a outros continentes. Ao conquistar a independência, em 1975, após quase quinze anos de guerra contra os portugueses, os líderes moçambicanos buscaram eliminar a língua do colonizador, mas isso se tornou impraticável ante à variedade de línguas presentes no país, que possuem importância regional, mas não alcance nacional. (Santiago, 2012)

Continuando, Santiago (2012) refere que ao todo Moçambique possui 43 idiomas, dos quais se destacam o macua, tsonga (shangaan), sena, lomwe, chuwabu e o nianja. $O$ tsonga, por exemplo, é falado pela etnia de mesmo nome, que está espalhada por Moçambique, África do Sul, Zimbábue e Suazilândia. Já a língua nianja, por sua vez, é falada pela etnia chewa e mais alguns povos próximos a eles, em Zâmbia, Zimbábue, Moçambique e Malawi, sendo que neste último país ela é oficial.

Para Marcer (1961) tribo e etnia são dois termos quase equivalentes. Uma etnia é um "grupo fechado, descendendo de um mesmo antepassado ou, mais geralmente, tendo a mesma origem, possuindo uma cultura homogénea e falando uma língua comum.

Por sua vez, Honigmann (1964) afirma que" em geral, os antropólogos estão de acordo sobre os critérios através dos quais uma tribo (como sistema de organização social) pode ser descrita como um território comum, uma tradição de descendência comum, uma linguagem comum, uma cultura comum e um nome comum.

Para a presente pesquisa, vai se caracterizar três etnias mais representativas de cada região de Moçambique, isto é, uma na zona norte, outra na zona centro e também na zona sul, comparando as suas identidades culturais.

Para Damatta (1986, p. 123), citado por Meque (2018) o termo cultura deriva do latim cultura, que significa acto de plantar e desenvolver plantas, actividades agrícolas. 
Associa-se também ao verbo latino colere (cuidar de plantas) cultivar. A palavra estava originariamente relacionado ao cultivo da terra. Acredita o mesmo autor que provavelmente, a relação anímica com a natureza como parâmetro para a compreensão do mundo, fez com que o termo agrícola passasse a traduzir, também, os padrões de comportamento sobre as normas, regras e conteúdos sociais e de relacionamento dos homens.

\section{O Macuas Lomués}

De acordo com Medeiros (1997), O povo macua é descendente de um grande povo Banto originário da região centro-africana (grandes lagos), ou seja das grandes florestas congolesas, que se migraram para a região da Africa Austral a procura de terras férteis. Este povo de lingua emakhuwa e elomwe estiveram representados no Niassa pelos macuas-lomwes, macuas-chirimas, e macuas-meto. Estes ammetho ocupavam desde o rio Lurio a nascente do messalo. Os macuas-lomues (alomwes), ocupavam a outra parte do rio Lurio e estes povos estiveram representados por linhagens de clãs exogamicos: alakassi, amirassi, anela, amale, amirolo, aseleja e achepani.

Actualmente este povo vive no norte de Moçambique, com cerca de 300.000 km2, abrange parte das províncias de Cabo Delgado, Niassa, Nampula, Zambézia, é delimitado ao norte pelo rio (Licungo nas proximidades) Rovuma a, leste o Oceano Indico, sul rio Licungo, próximo do rio Zambeze e o oeste rio Lugenda. Devido as migrações do sec XIX e ao tráfico de escravos nos séculos XVIII-XIX, pode se encontrar macuas também em Malawi, Tanzânia, Madagascar, Seychelles e Maurícias (Medeiros, 1997).

\section{Cultura como forma de identidade social}

Os macuás possuem umas características culturais específicas, sendo a capulana uma das vestes que os identifica.

Cabo Delgado é uma província de Moçambique que tem grande influência cultural dos países vizinhos, dentre eles, Tanzânia e Malaui. Além de encantar quem visita província, é desse contexto multicultural que surgem, por exemplo, as mulheres do povo makuwa bem vestidas de capulanas. Alem das capulanas, elas fazem pinturas bastante artísticas no rosto com o creme local chamado musiro. Essas mulheres chamadas 'Makuwas' ou do povo Makuwa, vestidas de cores de muito júbilo, ao tom do tambor e com o som agradável do elulu (estalo da língua) passam às vezes o dia todo cantando e dançando (Fonseca e Tristoni, 2013). 
Figura 1 Imagem de mulheres macuas com capulana como símbolo símbolo das suas vestes características e com musito na cara.

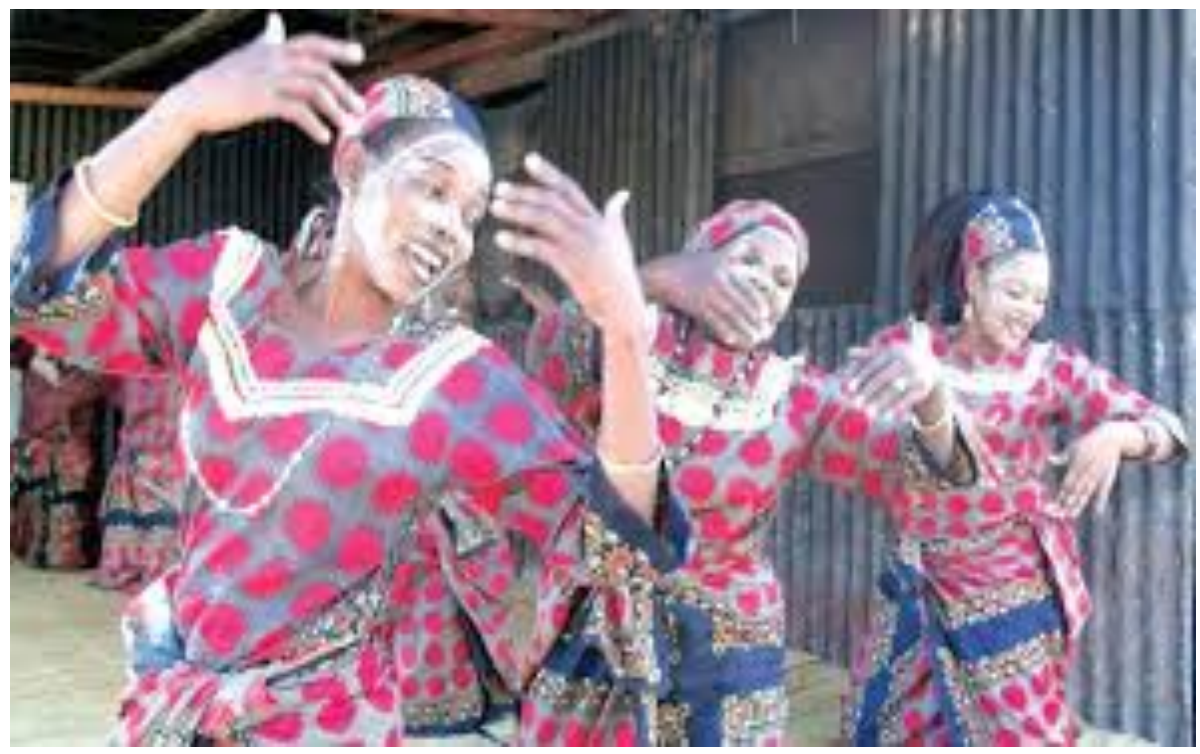

Fonte: Foto assessada no google.com/search aos 14/04/2020

Nas sociedades tradicionais em Moçambique, cada fenómeno humano representa um facto importante para a população, é neste âmbito que o nascimento nos macuas é acompanhado em ritos específicos.

Segundo Martrinez (1989) o nascimento de uma criança é um dos acontecimentos mais importante da sociedade macua. A criança é desejada e esperada pelos pais, responsáveis e membros da família, pelos habitantes e finalmente por todos os membros da sociedade, porque todos amam a vida e desejam que esta continue.

Cada vez que nasce uma criança este ideal realiza-se concretamente. Um outro filho significa, para a família e a sociedade, esperança concreta de que a vida não acaba, é sinal de que os antepassados continuam a ser intermediários entre a fonte da vida e a sociedade. Por isso o nascimento de uma criança é motivo de festa para toda comunidade, dia de alegria para todos (Martinez, 1989).

O povo Makuwa não tem registo de escrita em língua materna e suas histórias e seus costumes são revelados por meio da linguagem oral, através de rituais que estão presentes na vida do povo Makuwa, desde o nascimento até a morte. Todos estes rituais são expressos em língua materna do povo makuwa e, embora a língua oficial do país seja o português, a língua Emakhuwa acaba sendo a língua oficial do povo. Um exemplo disso são os chamados ritos de iniciação à vida adulta para as meninas, e a circuncisão (corte do prepúcio do menino), durante este ritual, os mais velhos transmitem conselhos aos meninos e os introduzem na vida adulta. Ressalta-se que o uso da Língua Emakhuwa 
torna-se evidente durante os momentos em que o povo makuwa se reúne para vivenciar seus costumes (Fonseca e Tristoni, 2013).

Fonseca e Tristoni (2013), continuam afirmando que: Já em relação à gastronomia, embora haja importação de cozinhas de outros povos como, por exemplos, os indianos, os árabes e os portugueses, a cozinha makuwa é bastante rica e tradicional. Há vários tipos de comida, tais como, "shima" (alimento feito de farinha de milho e de mapira, o nikujukhu (comida feita de milho pilado e feijão jugo), a matapa (uma mistura feita de folhas de mandioca), a mwatranka (uma espécie de polenta feita de farinha de mandioca). Estes alimentos revelam a identidade do povo Makuwa.

\section{O Ndaus}

As origens do povo Ndau não são fáceis de traçar devido a escassez de fontes e as contradições existentes. Contudo, parece seguro afirmar que as origens do grupo se encontram ligadas á fragmentação dos reinos do Muenemutapa e Dom Pire aos ciclos expansionistas de grupos linhageiros Shonas-Caraga, os Rozvi, dos planaltos centrais do Zimbabwe na direcção da costa litoral do indico (Malua et al, 2014).

Malua et al (2014) continua afirmando que, os Ndau são um grupo étnicos que habitam o vale do Zambeze, do centro de Moçambique até ao seu litoral, e leste do Zimbabwe ao sul do Mutare. Os ancestrais dos Ndaus eram guerreiros da Suazilândia que se juntaram com a população local, constituída etnicamente por Manikas, Tewes, Barwes nas províncias de Manica e Sofala. Os ndaus falam um idioma que pertencem a família linguística xona.

De acordo com vários autores, o termo Ndau teria sido aplicado a estas populações pelos invasores Nguni vindos do sul, que ocuparam esta região durante a segunda metade do séc. XIX. O termo relacionar-se-ia com a forma tradicional como estas populações saúdam um chefe, ou um estrangeiro importante, que é a de se ajoelharem, baterem as palmas e repetida e ritmicamente gritarem «ndau ui ui, ndau uiui» (Florêncio, 2002), citado por Marta Patricio (2011).

Dada a essa ligação histórica entre os Ndaus da Rodésia, actual Zimbabwe, a sua relação continua, mesmo com o eastabelecimento de fronteira, segundo testemunha Ptaricio (2011) quando cita Florêncio (2005), referindo que: "Com efeito, o estabelecimento do traçado das fronteiras moçambicanas não foi suficiente para implicar a ruptura de um conjunto de relações de subordinação política, com uma enorme componente mágico-religiosa, entre as chefaturas vaNdau moçambicanas e rodesianas. Apesar dos esforços das autoridades coloniais portuguesas, estas relações perpetuaram-se e, mesmo na actualidade, os chefes vaNdau moçambicanos sentem-se 
dependentes, ou subordinados, dos chefes zimbabweanos, pelo menos do ponto de vista mágico-religioso".

Segundo, Meque (2018) Os Ndau são fortemente influenciados pela crença do poder dos antepassados qu se manifesta através dos espiritos que se incorporam aos vivos, para dizer o que os vivos devem ou não devem fazer sobre determinados assuntos da família ou da comunidade. Do ponto de vista de convivência social, estas crenças orientam a comunidade para uma boa conduta social, criando assim uma harmonina na convivência familiar a partir do medo que os mortos podem fazer para os vivos. As crimónias, são acompanhadas de danças com batimentos rítmicos de batuques ou com as palmas da mão.

Continuando, Meque (2009) refere que: Duma forma geral, O povo Ndau pratica quatro (4) danças principais: Ndhokodo, Mandowa, Makwaia, Madjzhoka (esta última é cerimonial e espiritual e é exclusivamente ligado ao curanderismo). No entanto, como se referenciou, em Sofala, os Ndau estão principalmente em Machanga, Chibabava, Búzi e Cidade da Beira. Por isso, em cada distrito existem outras danças locais como são os casos de Mukapa no Búzi e Xiquema em Machanga. Contudo, algumas danças tendem a desaparecer pela infuência da globalização. 


\section{Obsevisto}

e-ISSN no $2447-4266$

Figura 2 Imagem de danças tradicionais com curandaeiros, uma das identifição cultural do povo Ndau.

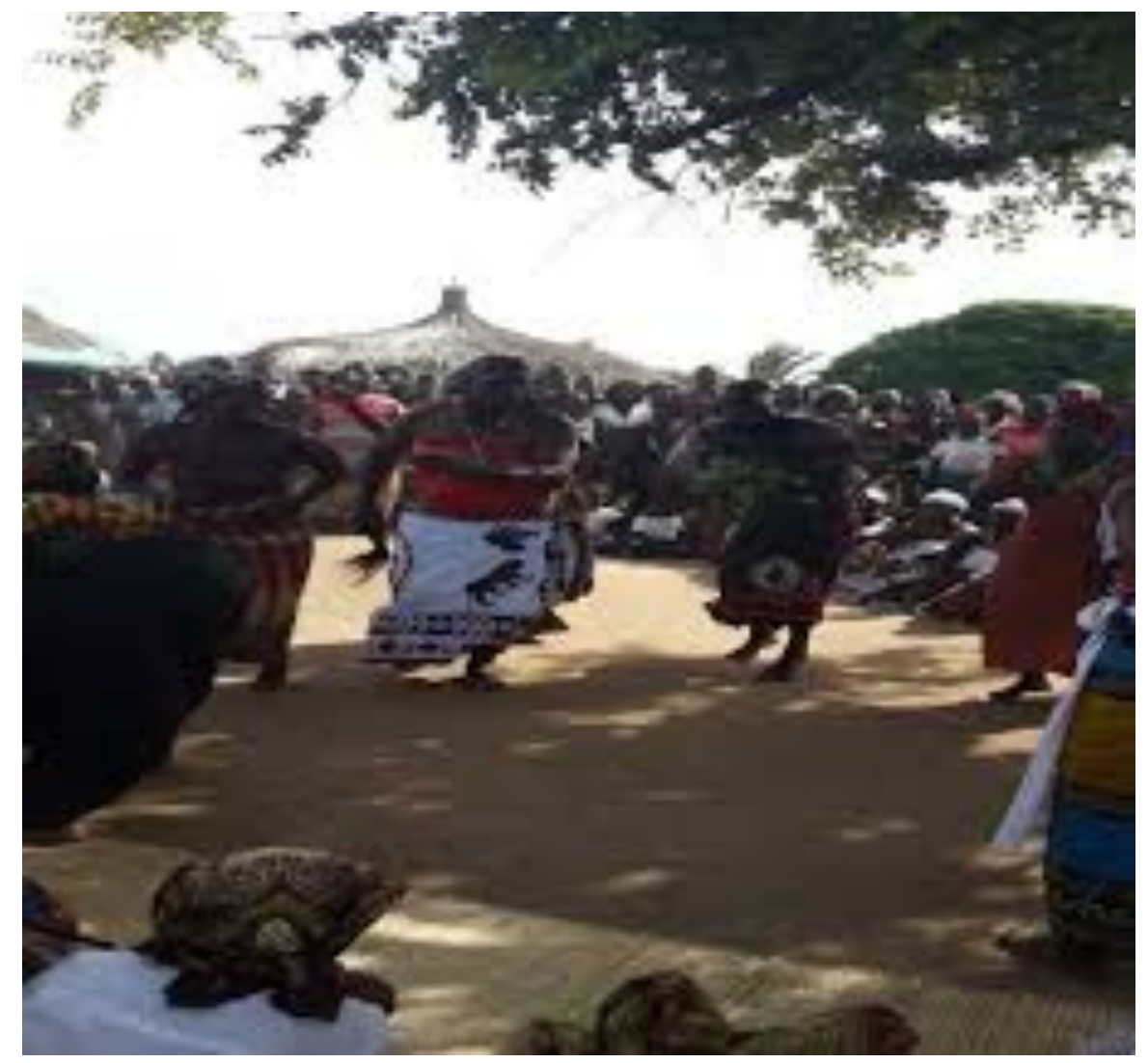

Fonte:

https://www.google.com/search?sxsrf=ALeKk01s1jgp22YMU6wus18OgbBkJjkUQ:158816472987 4.

\section{Os Tsongas}

Finalmente, vai se caracrerizar um dos grupos mais representativos da região sul de Moçambique, os Tsongas. Vejamos como Timbane (2014) citando Guthrie (1948) e Ngunga e Faquir (2011), caracteriza os tsongas:

"Tswa-ronga ou tsonga, segundo Guthrie (1948) é composta por três línguas: o xirhonga, o citshwa e o xichangana. Essas línguas são inteligíveis e ocorrem na região do sul de Moçambique, abarcando as províncias de Maputo, Gaza e Inhambane.

Segundo Ngunga e Faquir (2011) as línguas do grupo tsonga têm variantes: (a) xichangana: xihlanganu, xidzonga, xin'walungu, xibila e xihlengwe; (b) ronga: xilwandle, xinondrwana, xizingili e xihlanganu; (c) citshwa: citshwa, xikhambani, xirhonga, xihlengwe, ximhandla, xidzhonge e xidzivi. Esta subdivisão resulta de debates intensos em seminários entre linguistas moçambicanos e não só, na tentativa de se descrever e organizar a designação dessas línguas bantus moçambicanas." 
Por sua vez Junod (1996) citado por Coelho (2009), carateriza da seguinte maneira o povo tsonga: "A tribo tsonga compõe-se dum grupo de populações bantu estabelecidas na costa oriental da África do Sul, desde as proximidades da baía de Santa Lúcia, na costa do Natal, até ao rio Save, a norte. [...]

Os Tsongas confrontam ao sul com os Zulus e os Swazis; a oeste com os Mabis, os Lautis e outros clãs Suthu-pedis; ao norte com os Vendas e os Nyais no Zoutpansberg e na Rodesia e os Ndraws perto do Save; e a leste com os Tongas, perto de Inhambane, e os Copis ao norte da foz do Limpopo (Jnod, 1996: 33-4)."

Jundo (1996) falando de um dos aspectos que culturalmente, caracteriza os tsongas relacionada com advinhas, refere que:

"Um dos aspectos mais interessantes nestas representações sobre a natureza está circunscrito a uma das atividades mais centrais da vida tsonga: a adivinhação ou oráculo dos ossinhos. Denominado por Junod astragalomancia, em tsonga era conhecido como Nlholo ou Bula. Originário de kabula que significa "falar"; tinha o sentido de "A Palavra" ou "A Revelação". Esta prática religiosa visava diagnosticar as causas dos problemas que emergiam no seio das comunidades. Podiam ser de ordem diversa como doenças, cultivo, estiagem, negócios, política etc. O oráculo tenta prever, explicar e controlar quase todos os aspectos das aldeias e clãs tsongas (Junod, 1996: 463-4 -Tomo II)".

Outra das identidades culturais do povo tsonga, é o lobolo: "Lobolo é um costume cultivado até hoje no sul de Moçambique. A família da noiva recebe dinheiro pela perda que representa o casamento e a ida da filha para outra casa. No entanto, o lobolo tem significado de unir os antepassados das duas famílias (a do noivo e a da noiva), pedir aos antepassados que dêem sorte ao novo lar e sobretudo a fertilidade da noiva; garantir protecção da mulher na família do seu marido e finalmente passa a pertecer a família do seu marido; garantir o direito a noiva continuar na casa do marido a cuidar dos filhos, caso este morra (Langa, 2012)."

Segundo a caracterização do povo tsonga, feita por Ngunga e Faquir (2011) este grupo social, se subdivide em tantos outras etnias pequenas ou grandes que habitam a região sul de Moçambique. Um dos aspectos que reflecte esta caracterização, são as danças tradicionais.

De acordo com o site colgiomoz, na região sul de Moçambique encontramos as seguintes danças tradicionais: Timbila e zoré na Provincia de Inhambane, xigubo e makhwai nas provincias de Gaza e Maputo, Ngalanga na província de Maputo, xingomana na província de Gaza etc.

Figura 3 Imagem de uma das danças tradicionais da zona sul de Moçambique. 


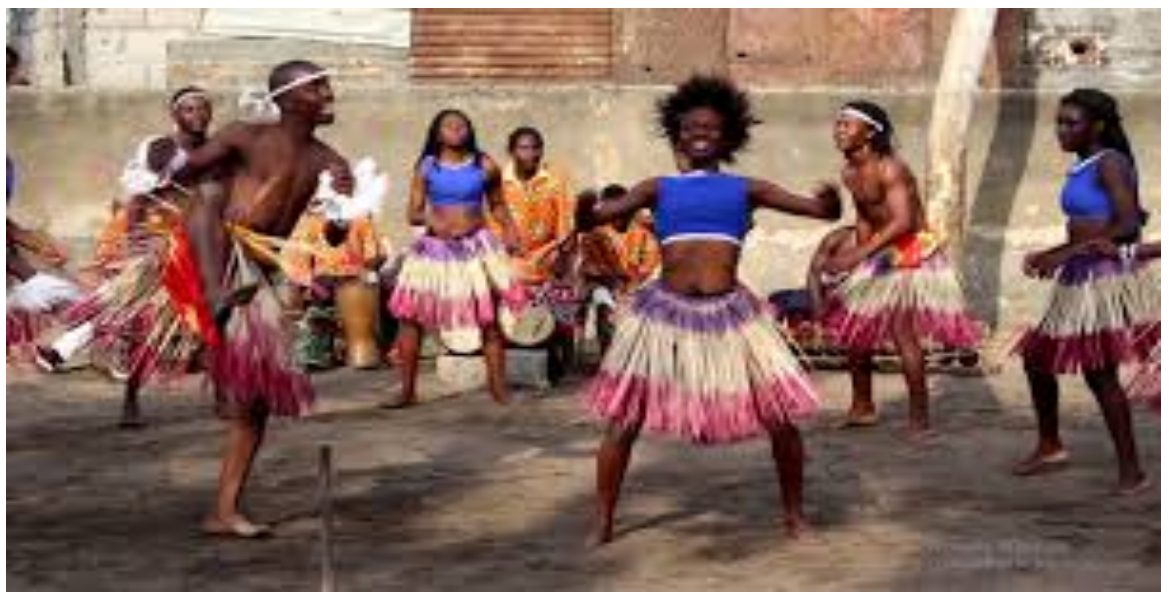

Fonte: www.colgiomoz.blogspot.com

\section{Conclusão}

Como foi dito atrás, o objectivo deste trabalho era o de fazer uma anlogia entre as teorias das representações sociais e algumas etnias que compõem o mosáico cultural moçambicano. A escolha das etnias macuas, ndaus e tsongas, foi uma concepção do autor não tendo se baseado a nenhum critério cientificamente estabelecido, contudo, julga-se que estas etnias, possam ser representativas dos diferentes extractos sociais/culturais moçambicanos.

Na abordagem teórica feita ao longo do trabalho, foi possível fazer uma ligação entre as teorias das representações sociais e características espicíficas de cada entia, se não vejamos:

Jodelet (1985) diz que as representações sociais, são modalidades de conhecimento prático orientados para a comunicação e para a compreensão do contexto social, material e ideativo em que vivemos.

Para Moscovici (1978) As Representações Sociais são entidades quase tangíveis. Elas circulam, cruzam-se e cristalizam-se incessantemente, por intermédio de uma fala, um gesto, um encontro em nosso universo cotidiano, constituindo, assim, uma modalidade de conhecimento particular que tem por função a elaboração de comportamentos e a comunicação entre os indivíduos.

Estas abordagens deste dois autores, encontram suporte na caracterização feita às três etnias acima analisadas, pois, foi possível notar como cada etnia interpreta o seu contexto desde o contexto histórico ao cultural, á interpretação do seu meio ou contexto e, a partir daí, moldarem-se comportamentos, idealizações do seu mundo e desenharem-se suas formas de comunicação e de convivência. 
Por sua vez Valá (1996) quando fala das representações sociais, diz que através da interacção, os homens encontram meios de explicalção sobre objectos de natureza social. Encontramos nestas três etnias a forma como a partir da sua interacção constroem a sua maneira de viver, os seus hábitos. Esta construção como foi constatado transmitese de geração a geração.

Um dos aspectos que foi notório na carcterização das etnias moçambicanas, foi a cultura que é uma das identidades principais de um grupo social determinado, daí que foram trazidas até imagens algumas características específicas de algumas manifestações culturais de cada etnia.

James (1890) fala do homem autónomo, como aquele que é o sujeito da acção e do homem plástico que é agido ou seja um sujeito passivo. Ao se fazer analogia desta abordagem de James pode se caracterizar a acção humana da interação, o homem autónomo, como aquele que reflecte no que no seu meio vê, tenta compreender e pode acrescentar valor no que foi estabelecido anteriormente pelos antepassados do seu grupo no que a interpretação do objecto diz respeito. $E$, o homem plástico quando passivamente cumpre as regras da sua sociedade pré-estabelecidas e que se transmitem de geração a geração.

Nas três etnias aqui analisadas, foi constatado este fenómeno de homem plástico mais dominante, pois, cada etnia conserva a interpretação dos fenómenos e dos objectos sociais aos princípios estabelecidos pelos seus antepassados, tais como os ritos de iniciação, as danças, as crenças aos espíritos e ao uso de ossadas para interpretar acontecimentos no seio do grupo.

Outro fenómeno importante que foi notório ao longo desta pesquisa bibliográfica, foi o facto de quer os Macuas, assim como os ndaus e tsongas, a sua representação social, não se cinge às fronteiras nacionais, tendo ligaçõs com países vizinhos, para o caso dos macuas com a Tanzania e outros países dos grandes lagos, para os ndaus, o seu cordão umbilicar tem ligações com Zimbabwe e os tsongas com Àfrica do Sula e Suazilândia. Aqui encontramos de facto a genese das representações sociais de que caracterizam pessoas unidas pela mesma interpretação do objecto social e da construção do conhecimento a partir da relação cognição- objecto, que vai moldar as crenças, cultura e valores comuns que vão ditar a sua conduta e comportamentos.

Sobre esta ligação interpaíses ou regional das etnias, é importante voltar a repisar o que Patrício (2011) diz sobre isso: Moçambique é uma invenção do colonialismo português no sentido em que corresponde a uma unidade político-territorial que não existia antes do processo de ocupação efectiva delineado na Conferência de Berlim. A sua constituição não contou com a participação das sociedades africanas, e por isso em 
larga medida a ideia de uma "moçambicanidade" tem sido muitas vezes encarada, em certas áreas, como uma imposição exógena, não obedecendo a lógica ou concepções dessas populações.

Por fim conclui-se que as três etnias escolhidas, podem dar uma ideia do "casamento" entre as teorias sobre as representações sociais analisadas num contexto das etnias moçambicanas.

\section{Referências}

Bandura A, A. (1986), Social Foundations of Thought and Action, Englewood Cliffs,914 Printece Hall.

Coelho, M. (2009), O Mundo natural dos tsongas no discurso de Henri Junod.em https://anpuh.org.br/uploads/anaissimposios/pdf/201901/15487720056012ea47 f989c 3836fa024222b5618c.pdf, assessado aos 01/05/2020.

Damatta, R. (1986). Exploração: um ensaio de sociologia interpretativa. Rio de Janeiro: Rocco.

Florêncio, F. (2002) Identidade Étnica e Práticas Políticas entre os vaNdau de Moçambique. Cadernos de Estudos Africanos, n 3, p. 39-63, Jul./Dez.

FlorêncioL, F.(2005) Ao Encontro dos Mambos - autoridades tradicionais vaNdau e Estado em Moçambique. Lisboa: ICS, 298 p.

Fonseca L., Tristoni L.H. (2013), Os desafios que o povo makhua encontra para manter sua cultura diante do plurilinguismo na região de cabo delgado, Mçambique, revista Travessia, Maputo.

Fuller, S., 1988. Social Epistemology. Bloomington and Indianapolis: Indiana University Press.

Guthrie, M. (1948) The classification of the bantu languages. Tese. (Doutorado em Linguística). University of London. London: IALU/ IOUP.

Honigmann, J. (1964) "Tribe", A dictionary of the social sciences, Glencoe, Free press. James, W. (1890), The Principies of Psychology, Nova lorque, Holt.

Jodelet, D. (1989). Les Représentations sociales: un domaine en expantion. Em D. Jodelet (org.), Les représentations Sociales. Paris: Press Universitary de France.

Jodelet, D.1985), La representación social: Fenómenos, concepto y teoría. In: Psicologia Social (S. Moscovici, org.), pp. 469-494, Barcelona: Paídos.

JodeletT, D. (2001). Representações sociais: um domínio em expansão.In D. Jodelet (Ed.), As representações sociais (pp. 17-44). Rio de Janeiro: UERJ.

Junod, A. (1996), Usos e costumes dos Bantu. Tomo I. Maputo, Arquivo Histórico de Moçambique.

LangaA, L.(2012), Cultura do povo Moçambicano, zona sul em http://liandralanga.blogspot.com/2012/01/cultura-do-povo-mocambicanozonasul.html,assessado aos 01/05/2020.

Malua, R. Maugente, J. Notice, T. Eeneio, S. Manuel, L. Muadissinar, D. (2014).

Etnologia dos Povos Africanos-Ndau. (em https://malua7rcbm.blogs.sapo.mz/etnologia-dos-povos-africanos-ndau-1656).

Martinez L. (1989) O povo macua e sua cultura, Moç. Press, Maputo Medeiros, E. (1997) A cultura Macua em http://culturamocambicana.blogspot.com/2017/07/etnia-macua. 


\section{Obsevisto}

Meque, C.(2018) Globalização e sua influência nos elementos da cultura ndau, análise do caso da dança Xiquema em https://wwwresearchgate.net/publication/323638750, aos 29/04/2020.

Mercier, P. "Remarques sur la signification du "tribalisme actuel" en Afrique noire », Cahiers internationaux de sociologie, (Paris, PUF), XXI, Julho-Dezembro, 1961, p. 65.

Moscovic, S. (1978) A Repesentação Social da Psicanálise, Rio de Janeiro. Zahar Moscovic, S. (1984). The Phenomenon of Social Representations. Em R. Farr \& S.

Moscovici (org.), Social Representations. Cambridge: University Press.

Ngunga, A.; Faquir A, O. (2011) Padronização da ortografia de línguas moçambicanas: relatório do $3^{\circ}$ seminário. Maputo: CEA/UEM, 2011.

Patrício,M.(2011) Identidade Étnica, Regional ou Transnacional? O caso Ndau, XI congreso Luso-Africano UFBA, Bahia.

Santiago, E. (2012) A Cultura Moçambicana. Em: https://www.infoescola.com/cultura/cultura-mocambicana/.

Spink, M. J. P.(1993) The Concept of Social Representations in Social Psychology. Cad. Saúde Públ., Rio de Janeiro, 9 (3): 300-308, jul/sep.

Tibane, A. (2014) A Análise Sóciodiscursiva da "Saudação" do Grupo Étnico Linguístico Tsonga em Moçambique em https://wwwresearchgate.net/publication/305680975.

Vala, J. (1996). Representações sociais: para uma psicologia social do pensamento social. In. Vala \& M. B. Monteiro (Eds.), Psicologia social. $2^{\mathrm{a}}$ ed (pp. 353-384). Lisboa: Calouste Gulbenkian.

Vigotsky, L. S., 1978. Mind in Society. Cambridge: Harvard University Press. https://www.colegiomoz.blogspot.com/2018/12/dancas-tradicionais-da-zona-sulde.html. 


\section{ABSTRACT:}

This article aims to bring a reflection on the theory of Social Representations from the perspective of Social Psychology. From the bibliographic review, an analogy is made between the theories of social representations, to a concrete society, in this case, the Mozambican society. Social representations have been a topic widely discussed by several and categorized authors, many of them addressing the relationship between cognition-knowledge, individual and society. For this purpose, three Mozambican ethnicities were analyzed, namely, Macuas-Lomués, Ndaus and Tsongas, in which, based on the bibliographic verification of their cultures, beliefs and values, a real analogy can be drawn between the theories on social and cultural representations. the behaviors of these ethnic groups, which make clear the different social representations in the different regions that form the country called Mozambique.The basis of the research was the bibliographic review, both to address the theoretical supports, as well as to address the Mozambican reality.

KEYWORDS Representations; Ethnicities; Macuas; Tsongas.

\section{RESUMEN:}

Este artículo tiene como objetivo traer una reflexión sobre la teoría de las Representaciones Sociales desde la perspectiva de la Psicología Social. A partir de la revisión bibliográfica, se hace una analogía entre las teorías de las representaciones sociales, a una sociedad concreta, en este caso, la sociedad mozambiqueña. Las representaciones sociales han sido un tema ampliamente discutido por varios y categorizados autores, muchos de ellos abordando la relación entre cognición-conocimiento, individuo y sociedad. Para ello, se analizaron tres etnias mozambiqueñas, a saber, Macuas-Lomués, Ndaus y Tsongas, en las que, a partir de la verificación bibliográfica de sus culturas, creencias y valores, se puede establecer una analogía real entre las teorías sobre las representaciones sociales y culturales. los comportamientos de estas etnias, que dejan en claro las diferentes representaciones sociales en las distintas regiones que conforman el país llamado Mozambique. La base de la investigación fue la revisión bibliográfica, tanto para abordar los soportes teóricos, como para abordar la realidad mozambiqueña.

PALABRAS-CLAVES: Representaciones; Etnias; Macuas; Tsongas. 